\title{
LABORATORY RESEARCH OF STORAGE OF PREDATORY TICK AMBLYSEIUS SWIRSKII
}

\author{
Valentyna Krutyakova ${ }^{1}$, Igor Limar ${ }^{1}$, Adolfs Rucins ${ }^{2}$, Volodymyr Bulgakov ${ }^{3}$ \\ ${ }^{1}$ Engineering and Technology Institute "Biotechnica", Ukraine; \\ ${ }^{2}$ Latvia University of Life Sciences and Technologies, Latvia; \\ ${ }^{3}$ National University of Life and Environmental Sciences of Ukraine, Ukraine \\ arucins@ltk.lv
}

\begin{abstract}
At different stages of the cycle of providing the agricultural producers with plant protection means, the producers and consumers of beneficial insects and ticks face a number of problems. In particular, during the production and application of the predatory ticks in certain periods a problem exists of inconsistency of the rate of delivery of the finished products to the needs of the end consumer. The impact of storage under conditions of lowered temperature (from $0{ }^{\circ} \mathrm{C}$ to $+15^{\circ} \mathrm{C}$ ) upon the biological parameters of the predatory tick Amblyseius swirskii: survival, fertility and migration activity was studied. Based on the statistical processing of the results of laboratory research on the PC, it was found that minimisation of the predator losses can be achieved at a storage temperature of $+6{ }^{\circ} \mathrm{C}$. In addition, to ensure the corresponding values of biological indicators, the storage period should not exceed 8 days. The obtained results allow the development of a new storage method for Amblyseius swirskii in order to solve the problem of the mismatch in the rate of supply of predatory ticks to the needs of the end user. The storage of the ticks at low temperatures for a period of more than 8 days during mass dilution for application on the plants is not justified. By introducing the storage of Amblyseus Svirsky at low temperatures, the proposed approach allows significant solution of the problem of uncoordinated rate of delivery of the finished products to the non-rhythmic demands of the final consumer.
\end{abstract}

Keywords: biomethod, technology, temperature, survival, migration activity.

\section{Introduction}

Over the past decade in the economically developed countries there has been increased attention of agricultural producers to a greater share of biological agents in the total amount of measures for the plant protection. This is due to both increased demand of the population for the products of organic farming, and legislative initiatives aimed at reducing the chemical insecticidal load, especially in greenhouses. At the same time, at different stages of the cycle of providing the agricultural producers with plant protection means, the producers and consumers of beneficial insects and ticks face a number of problems. In particular, during the production and application of the predatory ticks in certain periods a problem of inconsistency of the rate of delivery of the finished products to the needs of the end consumer (the farms) arises: sometimes the daily demand for products exceeds the average volumes of production that are determined by the design production capacities, sometimes, vice versa, - there is an excess of the shipped biological control agents. That is, there arises a problem of storing the live ticks. This completely applies to Amblyseius Svirsky. The predatory tick Amblyseius swirskii (Athias-Henriot, 1962) is used as an agent of the biological method in the protection of the vegetable and ornamental crops from the pests under closed ground conditions (greenhouses, hothouses, etc.). The indicated predator is offered on the market by world famous manufacturers of the biological methods of plant protection. According to the data published in the scientific periodicals, Svirsky amblyseus is one of those commercially available biomethod agents for which there is the greatest demand in most countries of the world where the biological method of the pest control is used [1]. The predatory tick Ambliseius Svirskogo is of beige colour, in size less than $1 \mathrm{~mm}$. The female tick lays several eggs (from 2 to 4 ) daily on the leaf blade of plants. At a temperature of $+25^{\circ} \mathrm{C}$ the entire development cycle from the egg to an adult insect takes about 6 days. At all stages of development the predator is very mobile and active. The main source of food are eggs and the whitefly larvae. The alternative sources of food are young larvae of different types of thrips, some other small insects, as well as pollen. An individual Amblyseius swirskii can consume 15-20 eggs or 10-15 young whitefly larvae per day or up to 5 thrips larvae per day. The life expectancy of the adult insects can reach 1.5 months.

One of the main methods that allows to store and transport predatory ticks for more than 2 days at relatively low losses is cooling of consumer package with substrate and biomaterial to temperatures within the range from $0{ }^{\circ} \mathrm{C}$ to $+15^{\circ} \mathrm{C}$. However, without taking special measures, the losses of the product under such conditions make up a significant percentage. Therefore, the researchers propose a 
number of methods aimed at reducing the above losses. In particular, during the storage of ticks at low temperatures it was proposed to artificially create and maintain in the consumer package the maximum possible relative humidity - up to $100 \%$. Experiments have demonstrated that such a local creation of hygrothermal conditions can significantly increase the survival of the predatory ticks [2-5]. Also it proved as a good method providing the predatory ticks with the common spider mite Tetranychus urticae as a feed (C. L. Koch, 1836), which was previously introduced into diapause [2, 6, 7]. Such feeding is carried out for a certain time before storing the predators at lowered temperatures. According to the existing points of view, an increased ability of the predators to withstand cold due to this measure is due to the synthesis in the body of the spider mite, when it is introduced into the diapause of substances that have the properties of cryoprotectants [7, 8]. The body's ability to increase its capacity to withstand low temperatures at a sudden sharp drop in the ambient temperature is known as rapid cold hardening $(\mathrm{RCH})$. For the predatory ticks $\mathrm{RCH}$ was studied in Neoseiulus californicus (McGregor, 1954) [9]. During this investigation the storage of this predator for 2 hours at a temperature of $-10^{\circ} \mathrm{C}$ led to the loss of $98 \%$ of the adult females. In the same hour, if prior to the indicated cooling, preliminary acclimatization was carried out for 1 hour at a temperature of $+5^{\circ} \mathrm{C}$, the mite loss was only $25 \%$. The highest ability to $\mathrm{RCH}$ in this experiment was demonstrated by the individuals of Neoseiulus californicus in the larval stage and, especially, in the egg stage. It succeeded to evoke a similar induction of $\mathrm{RCH}$ in Neoseiulus californicus by acclimatizing it for 2 hours at a temperature of $+30^{\circ} \mathrm{C}$ or by keeping the mite in the nitrogen atmosphere for $1-2$ hours. Lowering the temperature is not the only and indispensable condition when storing predatory mites. As a factor that contributes to better storage of Neoseiulus californicus is found sustaining in the habitation place of mites of increased relative humidity of $96 \%$ [10]. However, unlike the works [2-5], it was noted that ticks are stored at a temperature of $+25^{\circ} \mathrm{C}$. Quite a complete review of various aspects of the formation of certain physiological reactions of the phytoseid mites to external influences, including lowering the ambient temperature, is given by the researchers in [11]. Some researchers studied the storage of the Amblyseus Svirsky mite at a temperature of $+15^{\circ} \mathrm{C}$ for a week [12] and found out that the density of the predatory mites in the consumer package significantly decreases over time.

The purpose of the research is to determine the impact of storing the Amblyseus Svirsky tick at temperatures from $0{ }^{\circ} \mathrm{C}$ to $+10{ }^{\circ} \mathrm{C}$ upon the biological indicators of the culture, as well as to determine the optimal condition for keeping the ticks.

\section{Materials and methods}

At the first stage of the investigation the number of ticks that had survived depending on the storage temperature and the shelf life was determined, that is, a two-factor experiment took place. This supposed construction of an appropriate response surface. For this situation a central compositional plan was chosen on condition that the dispersion of the predicted response value at a certain point depends only on the distance from this point to the centre of the plan, and not on the direction to it.

Based on the results of preliminary rough experiments, it was concluded that storing a predatory tick at temperatures below $+2{ }^{\circ} \mathrm{C}$ and above $+10^{\circ} \mathrm{C}$ leads to an unacceptably large loss of the product. In addition, it was found that, if the predators were stored at temperatures within the range from $+2{ }^{\circ} \mathrm{C}$ to $+10{ }^{\circ} \mathrm{C}$ for more than 10 days, the amount of losses determined also the economic inexpediency of applying such a technique. Therefore for the experiment the following ranges were initially selected: temperature - from $+2{ }^{\circ} \mathrm{C}$ to $+10^{\circ} \mathrm{C}$, the shelf life - from 2 days to 10 days. Considering the use of the rotatable plan, these ranges were slightly expanded and reached from $0.3^{\circ} \mathrm{C}$ to $11.7^{\circ} \mathrm{C}$, and from 0.3 days to 11.7 days, respectively. The number of the full tanks was chosen equal to 3.70 ticks were placed in plastic containers that were hermetically sealed. The tanks were placed in thermostats. The predators were kept for 0.3 days, 2 days, 6 days, 10 days and 11.7 days at temperatures $+0.3{ }^{\circ} \mathrm{C},+2{ }^{\circ} \mathrm{C}$, $+6{ }^{\circ} \mathrm{C},+10^{\circ} \mathrm{C},+11.7$ days and nights, in total 11 storage options with three repetitions (Table 1 ). At the end of the storage period of each tank (a total of 33 tanks of 70 animals in each were examined), the number of surviving ticks was recorded.

After the optimal storage temperature was determined, in the next, the second stage, the fecundity of females that were stored under these conditions was studied. With this aim the adult fertilized females were placed in the Petri dishes on cut out round plates of pepper. Pepper pollen was introduced to Petri dishes as food. The Petri dishes were tightly closed with a cling film. Every day 
and night the ticks were transferred to new Petri dishes, and the number of the laid eggs was counted. For comparison the number of eggs that were laid by the females and were not previously stored at a low temperature was counted (control).

At the last, third stage, the migration activity of the ticks previously stored at a reduced temperature was studied. To do this, 100 individuals of the Amblyseus Svirsky predator were placed in $200 \mathrm{ml}$ polyethylene containers. The containers were placed in a thermostat at a previously determined optimal storage temperature. The shelf life of the ticks ranged from 1 day to 8 days. After storage, for each separate period, the ticks were placed in a graduated glass with a bottom diameter of $120 \mathrm{~mm}$ and a height of $150 \mathrm{~mm}$. The air temperature in the room during this experiment was maintained within the range from $+23{ }^{\circ} \mathrm{C}$ to $+25^{\circ} \mathrm{C}$ - the temperature range that is recommended in greenhouses for growing tomatoes and cucumbers. The time for the predators to reach the edge was recorded in a laboratory journal. The observation took place for 2 hours. The experiment was repeated three times. The following indicators were determined: the percentage of the predators that were not able to reach the edge of the glass for 2 hours, and the time during which $50 \%$ of the ticks reached the edge. The regression analysis was used to process the results.

\section{Results and discussion}

The data obtained during a series of experiments to determine the optimal storage temperature are shown in the table (Table 1).

Table 1

Dependence of survival of Amblyseius swirskii on the temperature and shelf life

\begin{tabular}{|c|c|c|}
\hline $\begin{array}{c}\text { Shelf life, } \\
\text { days }\end{array}$ & $\begin{array}{c}\text { Storage } \\
\text { temperature, }{ }^{\mathbf{o}} \mathbf{C}\end{array}$ & $\begin{array}{c}\text { Average number of the } \\
\text { surviving ticks, pcs. } \mathbf{\text { SE }} \\
\text { (standard error) }\end{array}$ \\
\hline 0.3 & +6.0 & $70.0 \pm 0.6$ \\
\hline 2.0 & +2.0 & $39.0 \pm 0.6$ \\
\hline 2.0 & +10.0 & $39.0 \pm 0.6$ \\
\hline 6.0 & +0.3 & $7.0 \pm 1.0$ \\
\hline 6.0 & +11.7 & $7.0 \pm 1.0$ \\
\hline 6.0 & +6.0 & $68.0 \pm 0.6$ \\
\hline 6.0 & +6.0 & $68.0 \pm 0.6$ \\
\hline 6.0 & +6.0 & $68.0 \pm 0.6$ \\
\hline 10.0 & +2.0 & $33.0 \pm 1.0$ \\
\hline 10.0 & +10.0 & $33.3 \pm 0.6$ \\
\hline 11.7 & +6.0 & $61.0 \pm 1.0$ \\
\hline
\end{tabular}

Statistical processing of the experimental data on the PC gave the following response surface:

$$
s=0.17+0.34 \tau-0.09 \tau^{2}+23.02 t-1.91 t^{2},
$$

where $s$-objective function - the number of surviving individuals, pcs;

$\tau$ - shelf life, days and nights;

$t$ - storage temperature, ${ }^{\circ} \mathrm{C}$.

The response surface is shown in Fig. 1.

Comparison of the calculated Cochren coefficient $G_{p}$ with the critical values of the Cochren coefficient $\mathrm{Gm}$ from the table, as well as the calculated Fisher coefficient $F_{p}$ with the critical value of the Fisher coefficient $F_{m}$ from the table $(\mathrm{p}=0.05)$ demonstrated that the obtained model, a secondorder polynomial, is consistent with the results of the experimental studies.

The response surface clearly demonstrates that at a certain temperature $\left(+6^{\circ} \mathrm{C}\right)$ there is a pronounced decrease in the losses of the product. However, it should be noted that it can be discussed about such a reduction in losses only in the context of the circumstances of the storage of ticks at a low temperature. Indeed, if the ticks are in a technocenosis for mass breeding (but not in the consumer's package) at an optimal temperature for their life, then the survival will be higher than the optimal storage temperature obtained during the experiment. As for the dependence of the product loss during 
its storage on time, as the response surface testifies, under conditions of low temperature, although the survival rate decreases with increasing the shelf life, however, the influence of this factor is very weak. In addition, no fluctuations and extremes are observed.

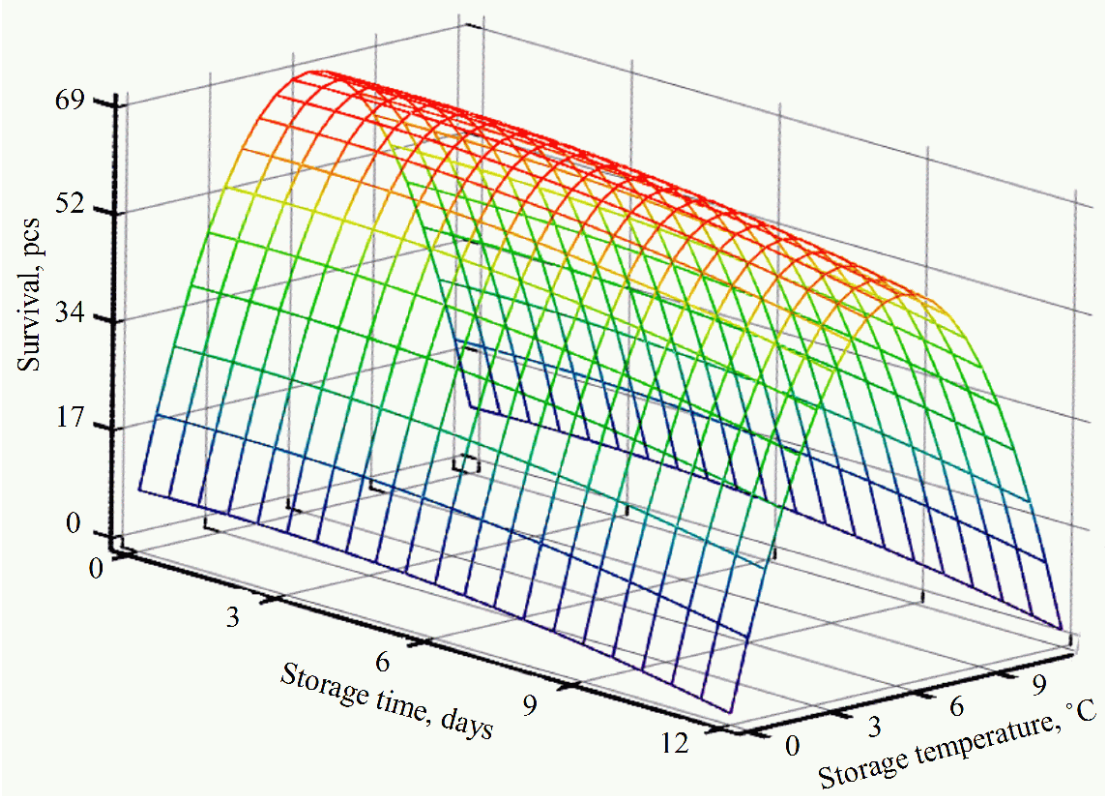

Fig. 1. Dependence of survival of the individuals Amblyseius swirskii on the temperature and the shelf life

The results of the experiment determining the average number of eggs laid by one amblyseus female after storage at the optimum temperature, which is $+6{ }^{\circ} \mathrm{C}$, are reflected in Fig. 2.

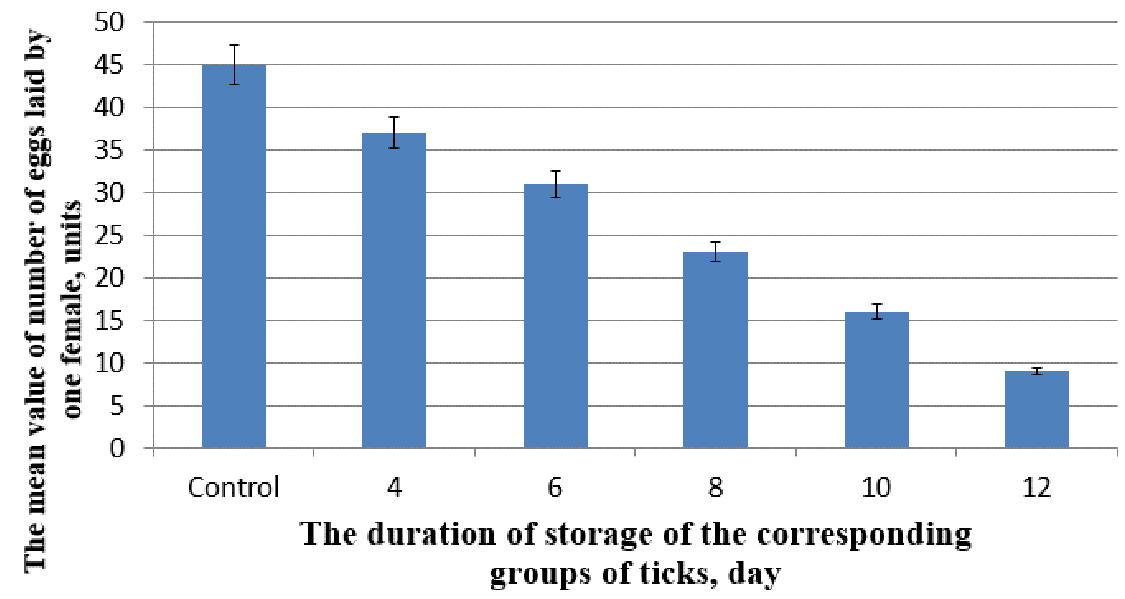

Fig. 2. Average number of eggs laid by one female after storage for different periods at the temperature of $6^{\circ} \mathrm{C}$ and in control (the temperature at breeding in technocenosis)

The results of the experiment in order to determine the degree of preservation of the activity of migration by the predatory mites after storage at the above optimal temperature are shown in the table (Table 2).

During the regression analysis, the dependence of the percentage of the predators that did not reach the edge of the laboratory capacity for 2 hours was obtained - a linear equation with the corresponding coefficients. The percentage of the ticks $y_{l}(\%)$ that did not reach the edge is determined by the relationship:

$$
y_{1}=2.286+3.500 X,
$$

where $\mathrm{X}-$ duration of the preliminary storage, days and nights. 
The dependence of the time for which $50 \%$ of predators reached the edge of the tank on the number of days and nights when the ticks were stored at a lowered temperature is presented by the quadratic parabola equation with the coefficients obtained by performing the regression analysis. The time $y_{2}$ (min.) during which $50 \%$ of the ticks reached the edge is determined by this dependence:

$$
y_{2}=11.540-0.420 X+0.210 X^{2},
$$

where $\mathrm{X}-$ duration of the preliminary storage, days and nights.

Table 2

Results obtained during the experiment in order to determine the degree of preservation of the Amblyseius swirskii migration activity after storage

\begin{tabular}{|c|c|c|}
\hline Shelf life, day and night & $\begin{array}{c}\text { Percentage of individuals that } \\
\text { did not reach the edge within 2 } \\
\text { hours, \% }\end{array}$ & $\begin{array}{c}\text { Time in which 50 \% of } \\
\text { individuals reached the } \\
\text { edge, min }\end{array}$ \\
\hline 1 & 6 & 11 \\
\hline 2 & 9 & 12 \\
\hline 3 & 13 & 12 \\
\hline 4 & 16 & 13 \\
\hline 5 & 20 & 15 \\
\hline 6 & 23 & 17 \\
\hline 7 & 27 & 19 \\
\hline 8 & 30 & 22 \\
\hline
\end{tabular}

\section{Conclusions}

1. The optimum storage temperature at which there is the least loss of the product is $+6{ }^{\circ} \mathrm{C}$, the maximum shelf life of the tick at the indicated temperature is 8 days.

2. Under these storage conditions, acceptable predator survival is observed, they retain the necessary biological parameters; and the further use of Amblyseus Svirsky as a biological control agent is possible and appropriate.

3. According to our estimates, the storage of the ticks at low temperatures for a period of more than 8 days during mass dilution for application on the plants is not justified.

4. By introducing the storage of Amblyseus Svirsky at low temperatures, the proposed approach allows significant solution of the problem of uncoordinated rate of delivery of the finished products to the non-rhythmic demands of the final consumer.

\section{References}

[1] Van Lenteren J.C. The state of commercial augmentative biological control: plenty of natural enemies, but a frustrating lack of uptake. BioControl. 2012, Vol. 57, Issue 1. pp. 1-20.

[2] Ghazy N.A., Suzuki T., Shah M., Amano H., Ohyama K. Using high relative humidity and low air temperature as a long-term storage strategy for the predatory mite Neoseiulus californicus (Gamasida: Phytoseiidae). Biological Control. 2012, Vol. 60, Issue 3. pp. 241-246.

[3] Ghazy N.A., Suzuki T., Shah M., Amano H., Ohyama K. Effect of long-term cold storage of the predatory mite Neoseiulus californicus at high relative humidity on post-storage biological traits. BioControl. 2012, Vol. 57, Issue 5. pp. 635-641.

[4] Ghazy N.A., Suzuki T., Amano H., Ohyama K. Effects of air temperature and water vapor pressure deficit on storage of the predatory mite Neoseiulus californicus (Acari: Phytoseiidae). Experimental and Applied Acarology. 2012. Vol. 58, Issue 2. pp. 111-120.

[5] Ghazy N.A., Suzuki T., Amano H., Ohyama K. Air temperature optimisation for humiditycontrolled cold storage of the predatory mites Neoseiulus californicus and Phytoseiulus persimilis (Acari: Phytoseiidae). Pest Management Science. 2014, Vol. 70, Issue 3. pp. 483-487.

[6] Ghazy N.A., Suzuki T., Amano H., Ohyama K. Humidity-controlled cold storage of Neoseiulus californicus (Acari: Phytoseiidae): effects on male survival and reproductive ability. Journal of Applied Entomology. 2013, Vol. 137, Issue 5. pp. 376-382. 
[7] Ghazy N.A., Ohyama K., Amano H., Suzuki T. Cold storage of the predatory mite Neoseiulus californicus is improved by pre-storage feeding on the diapausing spider mite Tetranychus urticae. Biocontrol. 2014, Vol. 59, Issue 2. pp. 185-194.

[8] Ghazy N.A., Osakabe M., Aboshi T., Mori N., Amano H. The effects of prestarvation diet on starvation tolerance of the predatory mite Neoseiulus californicus (Acari: Phytoseiidae). Physiological Entomology. 2015, Vol. 40, Issue 4. pp. 296-303.

[9] Ghazy N.A., Amano H. Rapid cold hardening response in the predatory mite Neoseiulus californicus. Experimental and Applied Acarology. 2014. Vol. 63, Issue 4. pp. 535-544.

[10] Ghazy N.A., Amano H. The use of the cannibalistic habit and elevated relative humidity to improve the storage and shipment of the predatory mite Neoseiulus californicus (Acari: Phytoseiidae). Experimental and Applied Acarology. 2016. Vol. 69, Issue 3. pp. 277-287.

[11] Ghazy N.A., Osakabe M., Negm M.W., Schausberger P., Gotoh T., Amano H. Phytoseiid mites under environmental stress. Biological Control. 2016, Vol.96. pp. 120-134.

[12] Lopez L., Smith H.A. Quality Assessment of the Commercially Available Predator Amblyseius swirskii (Acari: Phytoseiidae). Plant Health Progress. 2016, Vol. 17, Issue 3. pp. 206-210. 